\title{
Overview effect of three gorges reservoir on the changing water temperature in the Yangtze river, China
}

\begin{abstract}
The Yangtze River Basin is home to in excess of more than 400 million individuals and adds to about a portion of China's sustenance creation. Along these lines, getting ready for environmental change impacts on water asset releases is basic the readiness towards environmental change is necessary. The water temperature scope of the Yangtze River has changed essentially since the fruition of the Three Gorges Reservoir, which lead to a colossal impact on the water condition in the Three Gorges Reservoir. This investigation will analyze the effect of the Three Gorges Reservoir on the warm elements of the Yangtze River China. The investigation utilizes long haul perceptions of River Water Temperature. This paper centers on the investigation of the water temperature qualities of the standard qualities in the Three Gorges Reservoir and the slacking impact of water temperature on temperature structure contrasts in tributaries. The outcomes demonstrated that water temperature step by step diminished along the standard and stratified position water temperature of tributaries amid the warming time frame. Notwithstanding, water temperature step by step expanded along the standard, and water temperature stratification of the estuaries vanished in cooling period. After the consummation of the Three Gorges Reservoir, the effect of water temperature is predominantly reflected in slack qualities. Through further examinations, water temperature profiles will in general have great achievement when the Three Gorges Reservoir levels achieve $175 \mathrm{~m}$. This adds to water temperature contrasts in the tributary, which is the fundamental purpose behind water temperature structure changes. The methodology utilized here to evaluate the different commitments of atmosphere and human intercessions on River Water Temperature can be utilized to set logical rules for stream the executives, protection arranging and vital organic checking endeavors in controlled waterways.
\end{abstract}

Keywords: river water temperature, flow regime, yangtze river, three gorges reservoir China
Volume 3 Issue $3-2019$

\author{
Rawshan Othman Ali, 1,2 Shadan Rashid \\ Abubaker, ${ }^{3}$ Md Sahidul Islam' \\ 'College of Hydraulic and Environmental Engineering, China \\ Three Gorges University, China \\ ${ }^{2}$ Department of Petroleum, Koya Technical Institute, Erbil \\ Polytechnic University, Iraq \\ ${ }^{3}$ Department of Environmental Engineering, college of \\ Engineering, Knowledge University, Iraq
}

\begin{abstract}
Correspondence: Rawshan Othman Ali, College of Hydraulic and Environmental Engineering, China Three Gorges University, Yichang443002, Hubei, China, Email rawshan@ctgu.edu.cn
\end{abstract}

Received: June 08, 2019 | Published: June 26, 2019

\section{Introduction}

The Three Gorges Reservoir is the biggest water control project in the world contemporarily. The Three Gorges Reservoir has delivered colossal far reaching advantage, for example, flood control, power generation, navigation, irrigation, tourism and has advanced successful and productive financial and social improvement. Be that as it may Never the less, it has modified the hydrology make-up, sedimentation, and water quality in the Yangtze River district. ${ }^{1-4}$ The ecological effect of the Three Gorges Reservoir is described by fell, orderly and aggregate. $^{5-7}$ The impoundment of the Three Gorges Reservoir produces stamped changes to the oceanic and land condition. The first stream type Three Gorges is changed into a prolonged and profound supply pursued with critical water temperature structure changes. Stream hydrology, hydrodynamic conditions and waterway geology have been changed after water stockpiling. In the interim, stream speed, choppiness dissemination and water decontamination limit have diminished. ${ }^{8}$ Water temperature changes more often than not such that influences the survival, digestion and generation capacities of sea-going living beings (or its species structure and conveyance). At last, the procedure, structure and capacity of the vitality stream and material cycle in the amphibian biological system will be influenced..$^{9-12}$ The watershed method has largely been used for this study the effects of climatic conditions and human activities on water resources; though, it is limited by the constant modification to land use patterns usually smaller in large catchments than in small watersheds. ${ }^{13}$ After the task of the Three Gorges Reservoir, numerous residential and outside specialists gave close consideration attention to water temperature stratification in the store and its impact on the water condition in tributaries. ${ }^{14-17}$ Therefore an effective planning management and water resources development require an adequate knowledge of climate variability and land use forms on hydrological processes. ${ }^{18}$ The biggest distinction between the standard and tributaries when the impoundment of the Three Gorges Reservoir was the water temperature stratification structure and hydrodynamic conditions. ${ }^{19}$ The nonstop and regular change of the stream designs in the tributaries likewise came about because of the water temperature distinction between the standard and tributaries. In the long run, extraordinary thickness flows were seen in the tributaries and modified the water temperature structure and supplement dispersion which eventually influenced the water quality status in the tributaries. ${ }^{20,21} \mathrm{Up}$ until now, there were not many investigations about water temperature attributes in the standard of the Three Gorges Reservoir and its effect on the water temperature structure in the tributaries. The inflows of the Three Gorges Reservoir demonstrated a pattern of planarization, and another water temperature condition would be shaped in the Three Gorges Reservoir by virtue of the upstream course repositories. In any case, the precise changes that would occur for the water temperature 
structures and how to assess the aggregate impact of temperature in the standard of the Three Gorges Reservoir needs further investigation. The subsequent impacts on the water temperature structure in the tributaries have likewise gotten little consideration. ${ }^{22}$ Additionally, River water temperature is utilized as a general indicator of the seagoing environment wellbeing since it firmly impacts the physical, organic and concoction properties of water. A few precedents: oxygen dissolvability, oceanic living beings natural surroundings, and concoction response rates. ${ }^{23-26}$ Understanding the warm make-up of waterways is basic for water quality issues and successful fisheries the executives. Different investigations on River Water Tempreture have appeared warm conduct is unequivocally connected to both substantial scale atmosphere changes. ${ }^{27-30}$ and human-actuated annoyances (for example dam development, warm contamination, deforestation, freshwater withdrawal and so forth.) on a nearby scale. ${ }^{31-34}$ Also, River Water Temperature vacillations may happen over a wide scope of time scales (sub-daily, every day, week after week, occasional, yearly) contingent upon the predominant variables. ${ }^{35-38}$ A suspicion can be made that air temperature is the most vital indicator for River Water Temperature since it is the prevailing driver of warmth motions at the air-water interface. ${ }^{35-41} \mathrm{Be}$ that as it may, as pointed out by Arismendi et al. ${ }^{42}$ Toffolon and Piccolroaz ${ }^{43}$ and Sohrabi, et al. ${ }^{44}$ (just to make reference to some ongoing works), the direct measurable connection among Air Temperature and River Water Temperature may not generally be thorough because of the extra impact from different variables, principally stream. As a rule, absolutely factual models dependent on Air Temperature are along these lines not sufficient to foresee River Water Temperature (see for example the correlation among various sorts of models in Piccolroaz et al. ${ }^{45}$ ) making ready for physically based models. Notwithstanding being constrained by an unpredictable interaction among common warmth motions, the warm routine of waterways might be additionally confused by the nearness of anthropogenic weights. The development of extensive repositories exceedingly impacts the hydrological and warm regular structure of streams. Dams may influence downstream River Water Tempreture elements over reality, including the modifying of yearly stream designs. ${ }^{46-48}$ changing provincial groundwater framework. ${ }^{49,50}$ Discharging of hypolimnetic water from thermally stratified repositories, ${ }^{51-53}$ and the supply activities for temperature and stream control downstream of the dam. ${ }^{46}$ Generally, the thermal effect (cooling or heating) of reservoir regulations is has impacted on the most immediately downstream from the dam and dissipates with distance since the river itself has time to exchange heat with its surroundings. ${ }^{51,54}$ The effect is similar to the thermal influence of upstream lakes, ${ }^{45}$ but in the case of reservoirs the thermal dynamics are complicated by the sequence of hydraulic operations. Due to their potential adverse ecological impacts. ${ }^{55-57}$ The reliable quantification of the effects of dam construction and operations on River Water Temperature is a central issue in several studies on water resource management and freshwater ecology. ${ }^{58-60}$ Propose a simple yet effective approach to quantify such an effect by using the hybrid semiempirical model air2stream. ${ }^{43,45}$ To reproduce the thermal dynamics that a regulated river would have under natural conditions (absence of human interventions, e.g. upstream dam) conditions. The model has the advantage of retaining the limited data requirement of statistical models (i.e. using only air temperature and stream flow as inputs), while preserving the intimate physical structure derived from the governing energy budget. The air2stream model can be regarded as a data-driven tool where the model structure and the calibrating parameters are derived from observations. Along these lines, if the inherent properties of the framework are steady, the model parameters have high transferability impacts in time from aligned conditions to in secret periods which can be utilized to investigate the working of the present framework under examination. As a comparable ongoing utilization of the air2stream demonstrate, we allude the peruser to $\mathrm{R}^{\circ} \mathrm{aman} \mathrm{Vinn}^{\circ} \mathrm{a}$ et al. They likewise call attention to the partner air2water show was effectively tried for foreseeing lake surface temperature utilizing just air temperature as an indicator, ${ }^{61-64}$ and has been ended up being reasonable for environmental change ponders. ${ }^{63}$ As a critical contextual investigation, here we researched the effect of human development on the warm elements of the Yangtze River in China. Endeavors to detach this impact from the going with modification of ecological conditions, for the most part spoken to by Air Temperature changes maybe because of environmental change, the air2stream show was utilized to recreate the normal regular conditions that the Yangtze River would directly involvement without extensive scale human mediations. Explicitly focused on the implications from the development of the TGR, this investigation attempts to distinguish highlights of the warm make-up of waterways that are prevalently affected by dams and after that contrast the effects related and distinctive kinds of guideline (run-of-stream, stockpiling and cresting). The warm routine of managed and unregulated waterways was portrayed utilizing 15 measurements that depicted the extent, recurrence, term, timing, and rate of progress of water temperature. Results show that capacity and cresting dams appropriating at any rate for example $10 \%$ of the middle yearly overflow for the most part (I) diminished the extent of water temperature variety at regular, day by day, and sub-every day timescales and (ii) expanded the month to month mean water temperature in September. This provincial evaluation offers imperative understanding with respect to a summed up example of warm change by dams, and this data could be utilized to direct natural checking endeavors in managed streams. ${ }^{65}$ So the goals of the present work are to break down the qualities of water temperature dissemination along the standard in the Three Gorges Reservoir

\section{Literature review}

\section{Overview of the Yangtze river basin}

The Yangtze River positions as the longest waterway in Asia and the fourth biggest stream on the planet as far as water release, conveying a yearly water volume of $910 \times 109 \mathrm{~m}^{3}$ into the ocean. This contributes about $2.6 \%$ of the world's absolute crisp water conveyed to the sea. ${ }^{66}$ The Yangtze River begins from the QinghaiTibet Plateau at an elevation of $4000-5000 \mathrm{~m}$ and streams eastbound toward the East China Sea. It depletes a catchment of $1.8 \times 106 \mathrm{~km}^{2}$ and its standard is $6300 \mathrm{~km}$ long. The Yangtze River is commonly isolated into three compasses. ${ }^{67}$ The upper reach incorporates the zone upstream of Yichang, the Middle Yangtze River stretches out from Yichang to Datong station, and the lower achieve extends from Datong to the stream mouth (Figure 1). Dams and sluices determined by hydrological alteration and to determine the effect of dams on the hydrological condition at the stream gauge site the hydrologic alteration was calculated. ${ }^{68}$ The seepage bowl is portrayed by a subtropical, warm and wet atmosphere and is influenced by the Asian rainstorm season. The Indian summer rainstorm and the East Asian summer storm impact the upper and mid-lower bowls of the Yangtze River, individually. The normal bowl wide precipitation is 1070 mmy $^{-1}$, with $70 \%-80 \%$ of yearly precipitation and over $80 \%$ of water release packed in the wet season from May to October. 


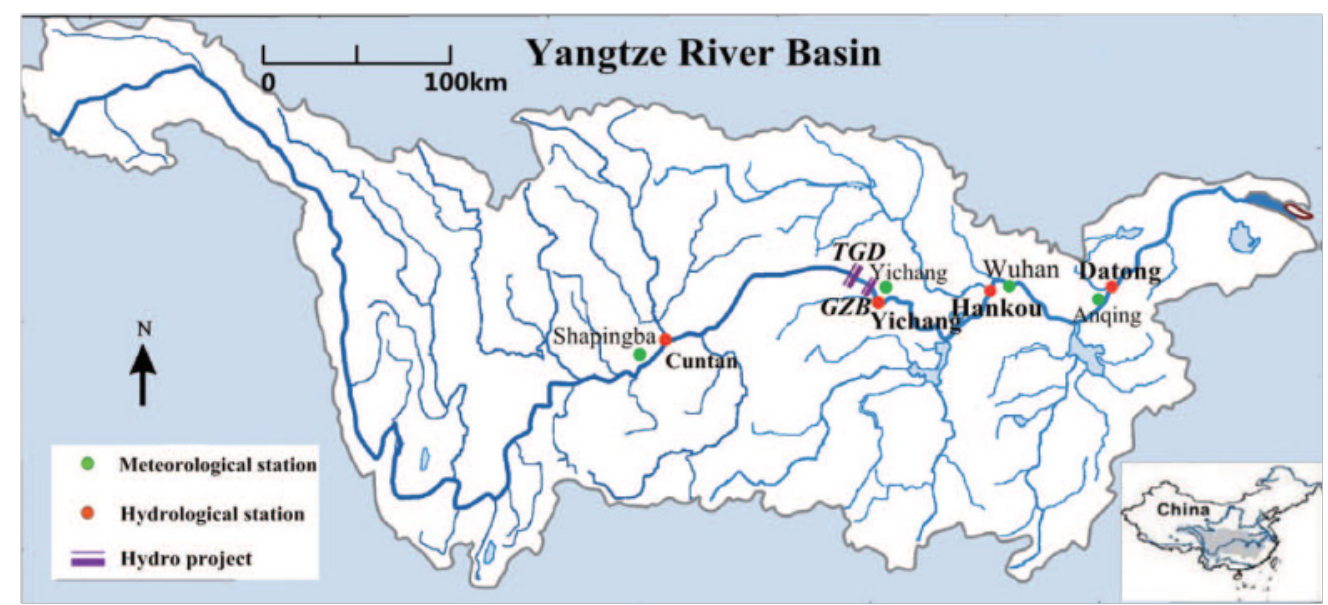

Figure I Map of the Yangtze River Basin displaying the observed meteorological and hydrological stations, conceptual sketch showing the distribution of major reservoirs, lakes, and hydrological stations along the Yangtze River. ${ }^{81}$

In excess of 50,000 dams have been built inside the Yangtze River basin since 1950's, extending in size from little impoundments on ranchers' fields to expansive dams overshadowing 100m high. ${ }^{69}$ Practically all dams are dispersed in the Yangtze River tributaries except for Three Gorges Dam and Gezhouba (GZB) situated along the standard. The Gezhouba dam was developed $6 \mathrm{~km}$ upstream of the Yichang Hydrological station and began to work in the mid 1980's with a stature of $47 \mathrm{~m}$, a width of $2595 \mathrm{~m}$, and an absolute stockpiling of $15.8 \times 108 \mathrm{~m}^{3}$. The TGD, finished in 2003 with a tallness of $185 \mathrm{~m}$, a width of $2335 \mathrm{~m}$, and an all out capacity of $393 \times 108 \mathrm{~m}^{3}$, was developed $44 \mathrm{~km}$ upstream of the Yichang Hydrological station. The Three Gorges Dam is worked with an occasional mode as per its numerous usage for flood control, water system, and power age. The Three Gorges Dam is the world's biggest power station regarding introduced control limit $(22,500 \mathrm{MW})$.

\section{River gauge data}

To comprehend the effect of human intercessions on the River Water Temperature, Based on regression analysis findings, changes in rainfall have a much bigger impact on its water resources quantity than changes in its air temperature ${ }^{70}$ we select the primary hydrological estimation stations Daily River Water Temperature, freshwater release (Q) at the hydrological stations as given by the Yangtze Water Resources Commission (see http://xxfb.hydroinfo.gov.cn). For each station to be examined, we will gather the day by day Air Temperature from the nearest meteorological stations (accessible at http://data.cma. cn). So as to measure the potential impact of the Three Gorges Dam on the waterway warm elements, we partitioned the time arrangement into a first pre- Three Gorges Dam period (before the development of the dam), and a second post- Three Gorges Dam period (with the working dam).

\section{Impact of the operation stage at three gorges dam}

The task organize at the Three Gorges Dam may apply critical effect on the downstream River Water Temperature through changes in the water volume put away in the store, and henceforth in its warm idleness. In June 2003, the Three Gorges Dam began to keep down water with the dimension ascending from 70-139m by October 2003. The water level pursued a regular variety somewhere in the range of $136 \mathrm{~m}$ and $143 \mathrm{~m}$ until 2006 (starting stage). Amid the transitional period, from October 2006 to October 2008, the water levels varied occasionally somewhere in the range of $145 \mathrm{~m}$ and $156 \mathrm{~m}$. In this way, it rose to $173 \mathrm{~m}$ in November 2008 and afterward to $175 \mathrm{~m}$ in October 2010 (standard typical stage).During standard ordinary stage, the water level in the TGD repository is seized to $175 \mathrm{~m}$ for power age amid the winter season, while it is purged to $145 \mathrm{~m}$ for flood control amid the late spring season. ${ }^{71}$ For the most part, water is put away from June to November, relating to expanding stream, for later discharge from December to March, bringing about diminishing stream to keep up power age and water supply amid the low stream conditions. ${ }^{30,71}$

\section{Impacts from temperature change}

Temperature change is a worldwide natural issue. In waterway bowls, temperature controls evapotranspiration, snow/ice sheet dissolve, and vegetation spread, and in this way, influences water and dregs releases. Temperatures inside the Yangtze Basin have expanded altogether since the mid 1980s disregarding the entomb yearly inconstancy. By and large, Bowl wide temperature expanded by $0.4^{\circ} \mathrm{C}$ between the 1950s and the pre-TGD decade (1993-2002), and has expanded by another $0.4^{\circ} \mathrm{C}$ in the post- Three Gorges Dam decade (2003-2012). This temperature increment concurs with the worldwide land temperature increment of a similar period In spite of the fact that it is hard to evaluate this impact in the present examination, ${ }^{72}$ the covariance among temperature and evapotranspiration is outlined by the precedent in 2006, when the bowl wide temperature was the most astounding and the water and residue releases were incredibly low. The release in 2006 was bizarrely beneath the pattern line between water release and precipitation, recommending the imperative factors other than precipitation that unequivocally influenced the release. In 2006, the consolidated impact of diminished precipitation and Three Gorges Dam can clarify just $58 \%$ of the water release decline. In the upper bowl of the Yangtze River, the fast temperature increment over the post- Three Gorges Dam decade may have quickened frigid and permafrost defrost. The icy masses in the source territory of the Yangtze River totaled $89 \mathrm{~km} 3$ before the $1980 \mathrm{~s}^{73}$ In the course of recent decades, the zone and volume of icy masses have diminished by $18 \%$ and $20 \%$, separately. ${ }^{74}$ The rate of ice liquefy was $0.07 \mathrm{~km}^{3} /$ yr. before 2003 and $0.99 \mathrm{~km}^{3} / \mathrm{yr}$. after 2003 . Accepting that the icy 
mass dissolve expanded by $0.9 \mathrm{~km} 3 / \mathrm{yr}$ from the pre- Three Gorges Dam to post- Three Gorges Dam decades, the expanded softening water would have contributed $9 \mathrm{~km} 3$ to the water release over 20032012. This release increment added up to $7 \%$ of the release from the source territory ( $8 \%$ of the Yangtze seepage bowl) of that decade, and brought about a $0.7 \%$ balance of the water release decline at Datong from the pre- Three Gorges Dam to post- Three Gorges Dam decades. We can in this manner reason that the net effect of bowl warming on water through evapotranspiration and defrosting of ice sheets and permafrost has been ca. 1\% of the release decline at Datong. Atmosphere warming may have likewise influenced the dregs motion. Higher temperatures increment the rate of shake weathering 40. In the source region of the Yangtze, the temperature in September-April is underneath $0^{\circ} \mathrm{C}$. Bowl warming may have abbreviated the snowfall season and expanded the precipitation aggravation of the surface soil. Defrosting of ice sheets and permafrost may have developed the surface disintegration zone. Be that as it may, as appeared, Such that, higher temperatures may have expanded evapotranspiration and brought about lower water and silt release. Thinking about the effects of different angles, ca. $1 \%$ of the residue motion decline at Datong in the post- Three Gorges Dam decade can be credited to higher temperature. ${ }^{75}$

\section{Impacts from water withdrawal/consumption}

Yearly water utilization/utilization in the Yangtze Basin started being accounted for in 1997 Mean yearly water use expanded by $\sim 20 \mathrm{~km}^{3} / \mathrm{yr}$, and mean yearly water utilization by $\sim 3 \mathrm{~km}^{3} / \mathrm{yr}$ between the pre- Three Gorges Dam and the post- Three Gorges Dam decades, which can clarify ca. $2 \%$ of the decreased water releases at Datong. Although an expanding pattern in yearly water utilization can be subjectively expected for the period before the pre- Three Gorges Dam decade, considering the fast increment in populace since the 1950s and the quick increment in financial action in the Yangtze Basin since the 1980s, it is hard to evaluate its effect on water release due to the absence of accessible information. There are two sorts of effects of water withdrawal on silt release. The primary effect is the result of suspended dregs focus (SSC) and measure of redirected water. Taking into account that $30 \%$ of the water preoccupation has been from stores with low SSC (information from CWRC) and that suspended residue in waterways are principally circulated close to the bottom 41 where water redirection isn't likely directed, the expanded silt preoccupation from the pre-to post- Three Gorges Dam decade was assessed to be under $2 \mathrm{Mt} / \mathrm{yr}$. On the off chance that the vast majority of these silt had not been redirected they would be caught in supplies, expanding dregs withdrawal most likely has decreased the residue transition at Datong by under $0.5 \mathrm{Mt} / \mathrm{yr}$. The second effect of water withdrawal is the decrease of capacity to transport residue, which is basic to the downstream disintegration. The effect of water preoccupation on the downstream disintegration, evaluated utilizing the exact connections of silt transport (Equations 16-21), was under $1 \mathrm{Mt} / \mathrm{yr}$. In this way, $<1 \%$ of the diminished dregs release at Datong from the pre-to postThree Gorges Dam decades can be credited to water withdrawal. ${ }^{75}$

\section{Impacts from the three gorges dam}

Three Gorges Dam has had two noteworthy consequences for water release. Right off the bat, proceeding with water impoundment in the Three Gorges Reservoir implied that water stockpiling expanded from $14 \mathrm{~km}^{3}$ in 2003 to $24 \mathrm{~km}^{3}$ in $2006,37 \mathrm{~km}^{3}$ in 2008 , and $39 \mathrm{~km}^{3}$ in 2010 . Furthermore, expanded dissipation in the Three Gorges Dam district because of progress from land to water surface (brought about a water loss of $0.3 \mathrm{~km}^{3} / \mathrm{yr}$ by and large averagely). The overall significance of the Three Gorges Reservoir on water release, obviously, has differed enormously year to year over the post- Three Gorges Dam decade. Amid the underlying filling of the Three Gorges Dam, expanded water stockpiling and vanishing aggregately diminished water release by 3 to $14 \mathrm{~km}^{3} / \mathrm{yr}^{75}$

\section{Impacts from other dams}

Ali Rawshan, ${ }^{76}$ confirmed that a decrease in precipitation and the construction of hydraulic structures reduced the flow in the river. The quantity of vast supplies (each with capacity limit $>108 \mathrm{~m}^{3}$ ) inside the Yangtze watershed expanded from zero out of 1950 to ca. 110 of every 1992, 140 of every 2002, and to 220 out of 2012. Correspondingly, the quantity of moderate sized supplies (with capacity limits $>107 \mathrm{~m}^{3}$ ) expanded from very nearly zero out of 1950 to $\sim 1300$ in 2012. The absolute water stockpiling in extensive and average sized supplies expanded from nil in 1950 to $40 \mathrm{~km}^{3}$ in 1992, to $64 \mathrm{~km}^{3}$ in 2002 , and $154 \mathrm{~km}^{3}$ in 2012 . Thus, the water stockpiling in all other vast and medium sized repositories expanded by $51 \mathrm{~km}^{3}$ from the pre-to post- Three Gorges Dam periods. Since this number does exclude commitments of the various little repositories, absolute water stockpiling most likely has expanded by ca. $60 \mathrm{~km}^{3}$, or 1.5 occasions more prominent than that of the Three Gorges Reservoir. Expanded vanishing is relative to expanded water stockpiling, as a result of comparability in supply bathy measurements and dissipation rate. It is found also that a dam/reservoir is the best option to control flood and mitigate drought, in term of volume. ${ }^{77}$ This diminishing is basically credited to dam development, since soil protection, another significant reason for the ongoing decrease in silt motion in the Yangtze River, did not start until the finish of the 1980s ${ }^{78-80}$ Notwithstanding this dam, numerous huge dams were developed in the center and lower Jinshajiang River in the last $50 \%$ of the post- Three Gorges Dam decade, and as much as or over $90 \%$ of the Jinshajiang residue may have been caught in their stores. ${ }^{75}$ Since the Three Gorges Reservoir caught $80 \%$ of the upstream residue over the $2003-$ multi decade. ${ }^{75}$ These silt, if not held behind dams upstream of the Three Gorges Dam, would for the most part have been caught in the Three Gorges Reservoir. Said another way, these dams have diminished the dregs surge from the Three Gorges Reservoir by ca. $17 \mathrm{Mt} / \mathrm{yr}^{75}$

\section{Other factors}

Different components incorporate urbanization, street development and tremors and so forth. Urbanization and street development in China have extraordinarily expanded in the most recent decade. While developing structures and streets, the ground is exposed to rain, which results to the formation of another residue and a more noteworthy residue yield can be normal. Upon the completing of development, the common surface is cleared with solid, which diminishes water invasion and expands spillover coefficient. Over the post- Three Gorges Dam period, a few brutal seismic tremors happened in the Yangtze Basin including the 8.0 greatness Wenchuan Earthquake that brought about the passing death of seventy thousand $(70,000)$ individuals. The quakes produced mudslides and may have expanded nearby residue yields. Be that as it may, in perspective on the bowl size of the Yangtze River, these variables are constrained to little territorial scales, and their far reaching impacts on the yearly water and silt releases are most likely extremely minor contrasted and the effects of the previously mentioned components. ${ }^{75}$ 


\section{Discussion}

In this examination, we researched the progressions in RWT elements of the Yangtze River, explicitly investigating and evaluating the different impacts of environmental change and human mediations. Perceptions demonstrate a predictable warming of RWT over the whole Yangtze River. With respect to the pre-TGD condition, the postTGD implies RWT expanded by $1.71^{\circ} \mathrm{C}$ and $0.06^{\circ} \mathrm{C}$ in cold and warm seasons, separately. ${ }^{81}$ By methods for the air2stream demonstrate, ${ }^{82}$ reproduced the potential RWT exclusively because of changes in the meteorological compelling (for example AT) and stream Q. Along these lines, we were likewise ready to measure alteration(s) that can be ascribed to the nearness of huge scale human mediations, basically spoken to by the TGD, in this way contrasting the recreated and watched RWT in the post-TGD period. Specifically, the mean winter RWT (December-February) expanded by $3.06^{\circ} \mathrm{C}$, while it extensively diminished by $1.76^{\circ} \mathrm{C}$ in spring (March-May). Be that as it may, The adjustments in the warm elements of the Yangtze River have been ineffectively revealed, which makes it hard to evaluate the potential effect of the TGD on the biological system wellbeing in the downstream reach of the Yangtze River. ${ }^{81}$ What's more, vast supplies and streams worldwide have been appeared to be vital wellsprings of ozone depleting substances with water temperature being one of the key controls of the outflow rates. ${ }^{64,75,83-93}$

\section{Conclusion}

After the seizing of TGR, the vertical slope of water temperature is insignificant, however there were contrasts in the longitudinal fluctuating backwater territory with a characteristic normal for the stream, the center area with extensive sufficiency of water temperature and the head with little changes of water temperature. The impact of slacking temperature bit by bit shaped in the underlying impoundment time frame and the impact of slacking temperature expanded continuously from 2003 to 2010 . These vacillations will in general be steady with the achievement of TGR seizing to $175 \mathrm{~m}$. The impact of slacking temperature adds to water temperature contrasts in tributaries. That is the fundamental motivation behind why water temperature structure continuously changed from three layer to two layer. Over the principal decade following the development of the TGD in 2003, the mean yearly water release from the Yangtze River to the ocean was $7 \%$ lower than that amid the period 1950- 2002 (and 13\% lower than that amid the period 1993-2002); the mean silt transition diminished by $71 \%$ in respect to $1950-1968$ (preceding decay) and diminished by $55 \%$ contrasted and 1993-2002. Notwithstanding, these decreases in water and residue releases were inferable not exclusively to the TGD yet in addition to numerous other normal and anthropogenic components. The post-TGD decade happened to be a dry period and the pre-TGD decade a wet period. Different supplies developed over the post-TGD decade have a consolidated stockpiling limit of 1.5 occasions bigger than the TGR and were progressively essential in the water release decline. We can hence infer that the decrease in stream water and dregs releases saw seen after development of a substantial dam can be created by different common and anthropogenic elements (far reaching assessment is required for both information and the executive systems). Toward this path, accepting the Yangtze River as a critical contextual investigation, our commitment gives a viable and straightforward strategy for measuring the effect of human exercises on RWT change. Such a novel methodology will, ideally, add to set logical rules for water assets chiefs and oceanic biologists.

\section{Future directions}

This investigation depicted a local layout of warm adjustment Yangtze River China. We distinguished two fundamental highlights of worry in the warm routine of these directed streams: the rate of progress in water temperature and the greatness of the warm routine. Discoveries propose the appropriated overflow list gives a profitable apparatus to work area appraisals of warm effects in ungauged bowls. This file could help draw an image of warm change by dams at the scene scalen. A decent comprehension of current warm effects at the scene scale gives basic setting to direct and organize dam evacuation endeavors. By distinguishing warm highlights of worry in managed streams, this examination featured potential systems fundamental changes in biological networks of controlled waterways. Further research can help gain a superior comprehension of the natural reaction related with the adjustment of individual warm highlights. For instance, ongoing endeavors have surveyed the biological ramifications of water temperature fluctuation at various timescales this exploration features the significance of such examinations given the change of this component in the warm routine of controlled waterways.

\section{Acknowledgments}

The authors wish to sincerely thank China Scholarship Council, China Three Gorges University for funding this study

\section{Conflicts of interest}

The authors declare that there is no conflict of interest.

\section{References}

1. Syvitski JPM, Vorosmarty CJ, Kettner AJ, et al. Impact of humans on the flux of terrestrial sediment to the global coastal ocean. Science. 2005;308(5720):376-380.

2. Skalak KJ, Benthem AJ, Schenk ER, et al. Large dams and alluvial rivers in the Anthropocene: the impacts of the Garrison and Oahe Dams on the Upper Missouri River. Anthropocene. 2013;2:51-64.

3. Fan H, He D, Wang H. Environmental consequences of damming the mainstream Lancang-Mekong river: a review. Earth Sci Rev. 2015;146:77-91.

4. Tang Q, Bao Y, He X, et al. Flow regulation manipulates contemporary seasonal sedimentary dynamics in the reservoir fluctuation zone of the Three Gorges Reservoir, China. Sci Total Environ. 2016;548:410-420.

5. Jackson S, Sleigh A. Resettlement for China's Three Gorges Dam: socioeconomic impact and institutional tensions. Communist Post-Communist Stud. 2000;33(2):223-241.

6. Chen KQ, Wang DS, Liu LF, et al. Features and research direction of environmental impact assessment for the planning of cascade hydropower development in river basins. J China Inst Water Resour Hydropower Res. 2005;3(2):79-84.

7. Zhong HP, Liu H, Geng LH. Cumulative effects of Lancang River basin cascade hydropower development on ecology and environment. J Hydraul Eng S. 2007;577-581.

8. Wu J, Huang J, Han X, et al. The three gorges dam: an ecological perspective. Front Ecol Environ. 2004;2(5):241-248.

9. Webb B, Walling D. Long-term variability in the thermal impact of river impoundment and regulation. Appl Geogr. 1996;16(3):211-223.

10. Caissie D. The thermal regime of rivers: a review. Freshw Biol. 2006;51(8):1389-1406. 
11. Elci S. Effects of thermal stratification and mixing on reservoir water quality. Limnology. 2008;9(2):135-142.

12. Yu Z, Yang J, Amalfitano S, et al. Effects of water stratification and mixing on microbial community structure in a subtropical deep reservoir. Sci Rep. 2014;4:5821

13. Othman Ali R, Chunju Z, Yihon Z, et al. The effects of human activities, climatic conditions and land-use factors on water resources development in huai river basin northeast china. Int J Hydro. 2018;2(2):112-118.

14. Jiao N, Zhang Y, Zeng Y. Ecological anomalies in the Eas China Sea: impacts of the three gorges dam? Water Res. 2007;41(6):1287-1293.

15. Yu ZZ, Wang LL. Factors influencing thermal structure in a tributary bay of Three Gorges reservoir. J Hydrodynam B. 2011;23(4):407-415.

16. Zheng TG, Mao JQ, Dai HC. Impacts of water release operations on algal blooms in a tributary bay of Three Gorges Reservoir. Sci China Technol Sci. 2011;54(6):1588-1598.

17. Cao GJ, Hui EQ, Hu XE. Analysis of the vertical structure of water temperature in the vicinity area of Three Gorges Dam since the Three Gorges Reservoir impounds. J Hydraul Eng. 2012;43(10):1254-1259.

18. Rawshan Othman Ali, Zhao Chunju, Zhou Yihon, et al. The Challenges of Water Resources Availability and Development in Huai River Basin, China. Article no.CJAST.38191. 2017;25(3):1-13

19. Liu L, Liu DF, Johnson DM, et al. Effects of vertical mixing on phytoplankton blooms in Xiangxi Bay of Three Gorges reservoir: implications for management. Water Res. 2012;46(7):2121-2130.

20. Ji DB, Liu DF, Yang ZJ, et al. Adverse slope density flow and its ecological effect on the algae bloom in Xiangxi Bay of TGR during the reservoir impounding at the end of flood season. J Hydraul Eng. 2010a;41(6):691696.

21. Yang ZJ, Liu DF, Ji DB, et al. Influence of the impounding process of the Three Gorges Reservoir up to water level $172.5 \mathrm{~m}$ on water eutrophication in the Xiangxi Bay. Sci China Technol Sci. 2010;53(4):1114-1125.

22. Liang-Hong Long, Hui Xu, Dao-Bin Ji, et al. Characteristic of the water temperature lag in Three Gorges Reservoir and its effect on the water temperature structure of tributaries. Environ Earth Sci. 2016;75:1459.

23. Wu GF, de Leeuw J, Skidmore AK, et al. Will the Three Gorges Dam affect the underwater light climate of Vallisneria spiralis L and food habitat of Siberian crane in Poyang lake. University of Twente. 2009.

24. Hester ET, Doyle MW. Human impacts to river temperature and their effects on biological processes: a quantitative synthesis. $J$ Am Water Resour As. 2011:47:571-587.

25. Yan Q. Impacts of the Three Gorges Dam on microbial structure and potential function. Sci Rep. 2015;5:8605.

26. Woodward G. The effects of climatic fluctuations and extreme events on running water ecosystems. Philos Trans R Soc B. 2016;371:20150274.

27. Van Vliet MTH, Ludwig F, Zwolsman JJG, et al. Global river temperatures and sensitivity to atmospheric warming and changes in river flow. Water Resour Res. 2011;47(2):W02544.

28. Garner G, Hannah DM, Sadler JP, et al. River temperature regimes of England and wales: spatial patterns, inter-annual variability and climatic sensitivity. Hydrol Process. 2014;28(22):5583-5598.

29. Rice KC, Jastram JD. Rising air and stream-water temperatures in Chesapeake Bay Region, USA. Clim Change. 2015;128(1-2):127-138.

30. Chen DJ, Hu MP, Guo Y, et al. Changes in river water temperature between 1980 and 2012 in Yongan watershed, eastern China: magnitude, drivers and models. J Hydrol. 2016;533:191-199.
31. Yang SL. Impact of Dams on Yangtze River Sediment Supply to the Sea and Delta Wetland Response. J Geophys Res. 2005;10:F03006.

32. Olden JD, Naiman RJ. Incorporating thermal regimes into environmental flows assessments: modifying dam operations to restore freshwater ecosystem integrity. Freshwater Biol. 2010;55(1):86-107.

33. Ding J, Jiang Y, Fu L, et al. Impacts of land use on surface water quality in a subtropical river basin: a case study of the dongjiang river basin, southeastern china. Water. 2015;7:4427-4445.

34. Chen P, Li L, Zhang HB. Spatio-temporal variability in the thermal regimes of the Danjiangkou reservoir and its downstream river due to the large water diversion project system in central China. Hydrol Res. $2016 \mathrm{~b} ; 47: 104-27$.

35. Webb BW, Clack PD, Walling DE. Water-air temperature relationships in a devon river system and the role of flow. Hydrol Process 2003;17(15):3069-3084

36. Caissie D, El-Jabi N, Satish MG. Modelling of maximum daily water temperatures in a small stream using air temperature. $J$ Hydrol. 2001;251:14-28.

37. Webb BW, Hannah DM, Moore RD, et al. Recent advances in stream and river temperature research. Hydrol Process. 2008;22(7):902-18.

38. Vanzo D, Siviglia A, Carolli M, et al. Characterization of sub-daily thermal regime in alpine rivers: quantification of alterations induced by hydropeaking. Hydrol Process. 2016;30(7):1052-1070.

39. Stefan HG, Preud'homme EB. Stream temperature estimation from air temperature. J Am Water Resour As. 1993;29(1):27-45.

40. Mohseni O, Stefan HG. Stream temperature air temperature relationship a physical interpretation. J Hydrol. 1999;218:128-141.

41. Sahoo GB, Schladow SG, Reuter JE. Forecasting stream water temperature using regression analysis, artificial neural network, and chaotic non-linear dynamic models. J Hydrol. 2009;378(3-4):325-342.

42. Arismendi I, Safeeq M, Dunham JB, et al. Can air temperature be used to project influences of climate change on stream temperature. Environ Res Lett. 2014.

43. Toffolon M, Piccolroaz S. A hybrid model for river water temperature as a function of air temperature and discharge. Environ Res Lett 2015;10:114011

44. Sohrabi MM, Benjankar R, Tonina D, et al. Estimation of daily stream water temperatures with a bayesian regression approach. Hydrol Process. 2017;31(9):1719-1733.

45. Piccolroaz S, Calamita E, Majone B, et al. Prediction of river water temperature: a comparison between a new family of hybrid models and statistical approaches. Hydrol Process. 2016;30(21):3901-3917.

46. Lowney CL. Stream temperature variation in regulated rivers: evidence for a spatial pattern in daily minimum andmaximum magnitudes. Water Resour Res. 2000;36:2947-2955.

47. Rounds SA, Wood T. Modeling water-quality in the Tualatin River, Oregon, 1991-1997. US Geol Surv Water Resour Invest Rep 2001-4041. Technical report US Department of the Interior and US Geological Survey, Portland, Oregon. 2001.

48. Sullivan A, Rounds S. Modeling streamflow and water temperature in the North Santiam and Santiam Rivers, Oregon, 2001-02: US Geological survey scientific investigations report 2004-5001 Technical report US Department of the Interior and US Geological Survey, Portland, Oregon. 2004

49. Constantz J, Essaid H. Influence of groundwater pumping on streamflow restoration following upstream dam removals. Hydrol Process. $2007 ; 21: 2823-2834$ 
50. Risley JC, Constantz J, Essaid H, et al. Effects of upstream dams versus groundwater pumping on stream temperature under varying climate conditions. Water Resour Res. 2010;46(6):W06517.

51. Preece RM, Jones HA. The effect of Keepit Dam on the temperature regime of the Namoi River Australia. River Res Appl. 2002;18(4):397414.

52. Yang DQ, Liu BZ, Ye BS. Stream temperature changes over Lena River basin in Siberia. Geophys Res Lett. 2005;32(5):L05401.

53. Zolezzi G, Siviglia A, Toffolon M, et al. Thermopeaking in Alpine streams: event characterization and time scales. Ecohydrology. 2011;4(4):564-576.

54. Toffolon M, Siviglia A, Zolezzi G. Thermal wave dynamics in rivers affected by hydropeaking. Water Resour Res. 2010;46:W08536.

55. Bruno D, Mart'inez-Capel F, Barqu'in J, et al. Effects of flow regime alteration on fluvial habitats and riparian quality in a semiarid Mediterranean basin. Ecol Indic. 2013;30:52-64.

56. Chen Q, Zhang X, Chen Y, et al. Downstream effects of a hydropeaking dam on ecohydrological conditions at subdaily to monthly time scales. Ecol Eng. 2015;77:40-50.

57. Grill G, Lehner B, Lumsdon AE, et al. An index-based framework for assessing patterns and trends in river fragmentation and flow regulation by global dams at multiple scales. Environ Res Lett. 2015;10:015001.

58. Cole JC, Maloney KO, Schmid M, et al. Developing and testing temperature models for regulated systems: A case study on the upper delaware river. J Hydrol. 2014;519:588-598.

59. Maheu A, St-Hilaire A, Caissie D, et al. Understanding the thermal regime of rivers influenced by small and medium size dams in eastern Canada. River Res Appl. 2016;32(10):2032-2044.

60. Kedra M, Wiejaczka L. Climatic and dam-induced impacts on river water temperature: assessment and management implications. Sci Total Environ. 2017;626:1474-1483.

61. Piccolroaz S, Toffolon M, Majone B. A simple lumped model to convert air temperature into surface water temperature in lakes. Hydrol Earth Syst Sci. 2013;17:3323-3338.

62. Piccolroaz S, Toffolon M, Majone B. The role of stratification on lakes' thermal response: the case of Lake Superior. Water Resour Res. 2015;51(10):7878-7894.

63. Piccolroaz S, Healey N, Lenters J, et al. On the predictability of lake surface temperature using air temperature in a changing climate: a case study for Lake Tahoe (USA). Limnol Oceanogr. 2018;63(1):243-261.

64. McGinnis D, Bilsley N, Schmidt M, et al. Deconstructing methane emissions from a small northern European river: hydrodynamics and temperature as key drivers. Environ Sci Technol. 2016;50:11680-11687.

65. Audrey Maheu, Andre St-Hilaire, Daniel Caissie, et al. A regional analysis of the impact of dams on water temperature in medium-size rivers in eastern Canada. Can J Fish Aquat Sci. 2016;73:1-13.

66. Dai A, Trenberth K. Estimates of freshwater discharge from continents: latitudinal and seasonal variations. J Hydrometeorol. 2002;3:660-687.

67. Fu C, Wu J, Chen J, et al. Freshwater fish biodiversity in the Yangtze River Basin of China: patterns, threats and conservation. Biodivers. Conserv. 2003;12(8):1649-1685.

68. Rawshan Othman Ali, Arez Mohammed Ismael, Muhammad Arif Mengal, et al. Influences of Three Gorges Dam on Flow Regime of Yangtze River, China. Journal of Engineering and Applied Sciences. 2019;14:5899-5905.

69. Yang SL, Milliman JD, Li P, et al. 50000 dams later: erosion of the Yangtze River and its delta. Glob Planet Change. 2011;75(1-4):14-20.
70. Rawshan Othman Ali, Arien Heryansyah, Nadeem Nawaz. Impact of climatic change on water resources in Huia river basin, China. International Journal of Engineering \& Technology. 2018;7(4):2225-2230.

71. Li C, Yang SY, Lian EG, et al. Damming effect on the Changjiang (Yangtze River) river water cycle based on stable hydrogen and oxygen isotopic records. J Geochem Explor. 2016;165:125-33.

72. Stocker TF. Climate Change (2013). The Physical Science Basis. Cambridge University Press, Cambridge. 2013.

73. Yao T, Yao Z. Impacts of glacial retreat on runoff on Tibetan Plateau. Chinese J Nat. 2010;32:4-8.

74. Wu JJ. Second investigation on glaciers in China. 2014.

75. Yang SL. Downstream sedimentary and geomorphic impacts of the Three Gorges Dam on the Yangtze River. Earth Sci Rev. 2014;138:469-486.

76. Ali Rawshan. Long Term Historic Changes in the Flow of Lesser Zab River, Iraq. Hydrology. 2019;6(1):22.

77. Ali R, Heryansyah A. Watershed retention capacity approach for identifying water resource problems-case study from malaysia. Polytechnic Journal. 2018;8(1).

78. Xu K, Milliman JD, Yang, et al. Yangtze sediment decline partly from Three Gorges Dam. EOS. 2006;87(19):185-196.

79. Yang ZS. Dam impacts on the Changjiang (Yangtze) River sediment load to the sea: the past 55 years and after the Three Gorges Dam. Water Resour Res. 2006;42(4)

80. Yang SL, Zhao QY, Belkin IM. Temporal variation in the sediment load of the Yangtze River and the influences of the human activities. J Hydrol. 2002;263:56-71.

81. Huayang Cai, Sebastiano Piccolroaz, Jingzheng Huang, et al. Quantifying the impact of the Three Gorges Dam on the thermal dynamics of the Yangtze River. Environ Res Lett. 2018;13(2018):054016.

82. Toffolon M, Piccolroaz S, Majone B, et al. Prediction of surface temperature in lakes with different morphology using air temperature. Limnol Oceanogr. 2014;59(6):2185-2202.

83. Chen $\mathrm{H}, \mathrm{Wu} \mathrm{YY}$, Yuan XZ, et al. Methane emissions from newly created marshes in the drawdown area of the three gorges reservoir. $J$ Geophys Res. 2009;114:D18301.

84. Yang SL, Xu KH, Milliman JD, et al. Decline of Yangtze River water and sediment discharge: Impact mfrom natural and anthropogenic changes. Scientific Reports. 2015;5:12581.

85. Huang W, Bi Y, Hu Z, et al. Spatio-temporal variations of GHG emissions from surface water of xiangxiriver in three gorges reservoir region China. Ecol Eng. 2015;83:28-32.

86. Li Z, Lu L, Lv P, et al. Carbon footprints of pre-impoundment clearance on reservoir flooded area in China's large hydro-projects: implications for GHG emissions reduction in the hydropower industry. J Clean Prod. 2017;168:1413-1424.

87. Marzadri A, Dee M, Tonina D, et al. Role of surface and subsurface processes in scaling N2O emissions along riverine networks. Proc Natl Acad Sci USA. 2017;114:4330-4335.

88. Coker GA, Portt CB, Minns CK. Morphological and ecological characteristics of Canadian freshwater fishes. Canadian Manuscript Report of Fisheries and Aquatic Sciences 2554. Fisheries and Oceans Canada. 2001.

89. Niehaus AC, Angilletta MJ, Sears MW, et al. Predicting the physiological performance of ectotherms in fluctuating thermal environments. J Exp Biol. 2012;215:694-701. 
90. Siberian crane in Poyang Lake. Hydrobiologia. 623;213-22.

91. Steel EA, Tillotson A, Larsen DA, et al. Beyond the mean: The role of variability in predicting ecological effects of stream temperature on salmon. Ecosphere. 2012;3(11):104.

92. Sullivan A, Rounds S. Modeling water-quality effects of structural and operational changes to Scoggins Dam and Henry Hagg Lake, Oregon: US geological survey scientific investigations report 2006-5060 Technical report US Department of the Interior and US Geological Survey, Portland, Oregon. 2006.

93. Yang L, Lu F, Zhou X, et al. Progress in the studies on the greenhouse gas emissions from reservoirs. Acta Ecol Sinica. 2004;34(4):204-212. 